Ann. Biol. anim. Bioch. Biophys., 1979, 19 (4 A), 989-997.

\title{
Modifications in the plasma membrane of elongated ram spermatids : A cytochemical study
}

\author{
par J. L. COURTENS
}

Station de Physiologie de la Reproduction, I.N.R.A., Nouzilly 37380 Monnaie, France.

Summary. Specific contrast of spermatid membranes was obtained using thiocarbohydrazide and silver proteinate staining applied on sections of ram testis, rapidly fixed and embedded in Spurr's medium. The contrast first appeared in the Golgi cisternae of young spermatids before becoming apparent in the proacrosomal granules, which later showed no more contrast while the acrosomal membrane began to stain. Some stained parts of that membrane were emitted in the cytoplasm of early elongating spermatids as postacrosomal vesicles (Courtens, 1978a). These vesicles were carried to the posterior cytoplasm of elongated spermatids, following a well-defined route into the cell. They finally fused with the plasma membrane which was progressively stained with the cytochemical procedure used. The controls might indicate the staining of lipid-associated subtsance(s).

\section{Introduction.}

In the last 10 years several surface components, specific to male germinal cells, have been described. Immunological techniques indicate that at least one of these molecules, namely the F9 antigen, is present in the cell membrane of all types of male germ cells (Gachelin ef al., 1976), while other components are first seen in the membrane of pachytene spermatocytes and are still found in spermatozoa (O'Rand and Romrell, 1977 ; Tung and Fritz, 1978).

Recent investigations indicate that the spermatozoon plasma membrane has specialized regions (Fawcett, 1975 ; Koehler, 1978) ; some components of these regions appear in young spermatids and then disperse in the plasma membrane due to a capping phenomenon (Romrell and O'Rand, 1978), while others are preferentially distributed around the acrosome or the mid-plece covering membrane. Some components are only encountered on the flagellum or found all over the spermatozoon (Millette and Bellve, 1977). Components appearing in the oldest spermatids have been reported by Johnson and Hunter (1972) and Baccetti et al. (1978). The latter authors described a component of the plasma membrane, covering the spermatid tail, that is synthesized by the Golgi apparatus of the spermatids of some species.

Using ultrastructural and cytochemical methods, the present study attempts to demonstrate that the postacrosomal vesicles, described earlier (Courtens, $1978 a, b$ ) as part of the acrosomal membrane and emitted in the cytoplasm of stage 7-9 ram spermatids, finally fuse with the plasma membrane adding some substances to it. 

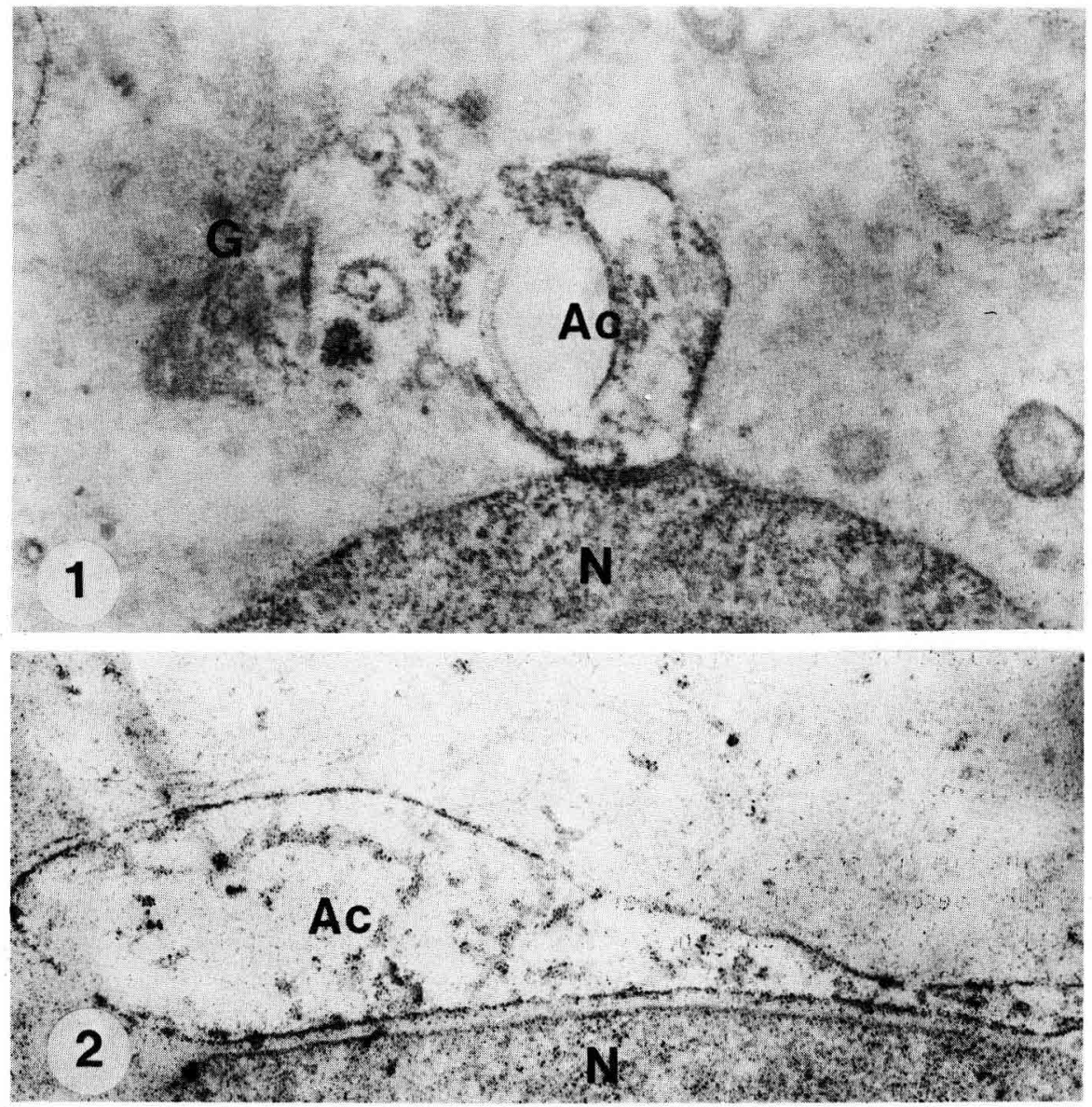

\section{PLATE I}

FIG. 1. - Stage 2 spermatid. Golgi apparatus (G), acrosome (AC) nucleus are stained with aqueous thiocarbohydrazide and silver proteinate. $30 \mathrm{~min}$ fixation ; embedding with Spurr's medium. $\times 20000$.

FIG. 2. - Stage 4 spermatid. Acrosomal membrane (AC) and diffuse material dispersed in the acroplasm are stained. Aqueous thiocarbohydrazide and silver proteinate staining. $30 \mathrm{~min}$ fixation ; embedding with Spurr's medium. $\times 25000$. 


\section{Material and methods.}

Thiocarbohydrazide-silver proteinate staining of lipid-associated substance(s).

Pieces of lle-de-France ram testis were immersed for 15 or $30 \mathrm{~min}$. at 4 or $20^{\circ} \mathrm{C}$ in 4 p. 100 glutaraldehyde dissolved in $0.1 \mathrm{M}$ phosphate buffer $(\mathrm{pH} \mathrm{7.4),} \mathrm{washed} \mathrm{in}$ distilled water for $1 \mathrm{~min}$., dehydrated at $4^{\circ} \mathrm{C}$ in $100 \mathrm{p}$. 100 ethyl alcohol for $2 \times 10 \mathrm{~min}$. and then embedded in either rapid-curing Spurr medium (Spurr, 1969) or epon (Luft, 1961). The ultrathin sections mounted on bare gold grids were stained with either 1 p. 100 aqueous thiocarbohydrazide (TCH) for 2 hrs at $60^{\circ} \mathrm{C}$ or $0.2 \mathrm{p} .100 \mathrm{TCH}$ dissolved in 20 p. 100 acetic acid for 24 hrs at $20^{\circ} \mathrm{C}$, according to Thiéry (1967). Affer several rinses in distilled water, they were floated on 1 p. 100 aqueous silver proteinate (Roques, Paris) for $30 \mathrm{~min}$. in darkness.

The controls were processed as follows :

- some tissues were fixed for $1 \mathrm{hr}$ or more with glutaraldehyde ;

- tissues fixed for 15 or $30 \mathrm{~min}$. were extracted with 100 p. 100 ethyl alcohol or acetone for 1 to $24 \mathrm{hrs}$ at $4{ }^{\circ} \mathrm{C}$ before embedding as described above ;

- before staining with TCH and silver proteinate, ultrathin sections were either (i) extracted with 100 p. 100 alcohol or acetone for 1 to $24 \mathrm{hrs}$ at $20^{\circ} \mathrm{C}$, (ii) treated with 5 p. 100 aqueous sodium sulphite for $4 \mathrm{hrs}$ at $37^{\circ} \mathrm{C}$ (Ganter and Jolles, 1969), or (iii) treated with phenylhydrazide for 4 hrs at $37^{\circ} \mathrm{C}$;

- some sections were stained with silver proteinate alone or with uranyl acetate and/or lead citrate. Spermiogenetic stages were evaluated according to Clermont and Leblond (1955).

\section{Results.}

The stalks of the Golgi apparatus were outlined in stage 1 to 3 spermatids, as well as the proacrosomal granules of stage 1 spermatids. The membrane of the proacrosomal vesicle and dispersed material inside the acrosome (fig. 2) stained in stage 2 (fig. 1), while the acrosomal granule was unreactive after stage 3 . The acrosomal membrane was the only structure stained in stages 3 to 7.

The postacrosomal vesicles, described previously as the parts of the acrosomal membrane emitfed in the cytoplasm of stage 7 to 9 ram spermatids (Courtens, 1978a), presented a stained membrane; postacrosomal vesicle movement in the cytoplasm could thus be followed during spermiogenesis. These vesicles slipped backwards along the nucleus to concentrate near the centrioles of stage 10 spermatids, and then migrated backwards between the posterior cytoplasmic channel and the manchette of stage 11 spermatids (fig. 3). They then passed to the rear of the posterior edge of the manchette and were dispersed in the posterior cytoplasm of stage 11 and 12 spermatids (fig. 4) before disappearing. At these stages, pictures resembling postacrosomal vesicle fusion with the plasma membrane (fig. 5) were occasionally obtained. The plasma membrane, weakly stained in stages 9 and 10 (fig. 3), was intensely and discontinuously stained around the posterior cyloplasm of stage 11 spermatids (fig. 6). The 

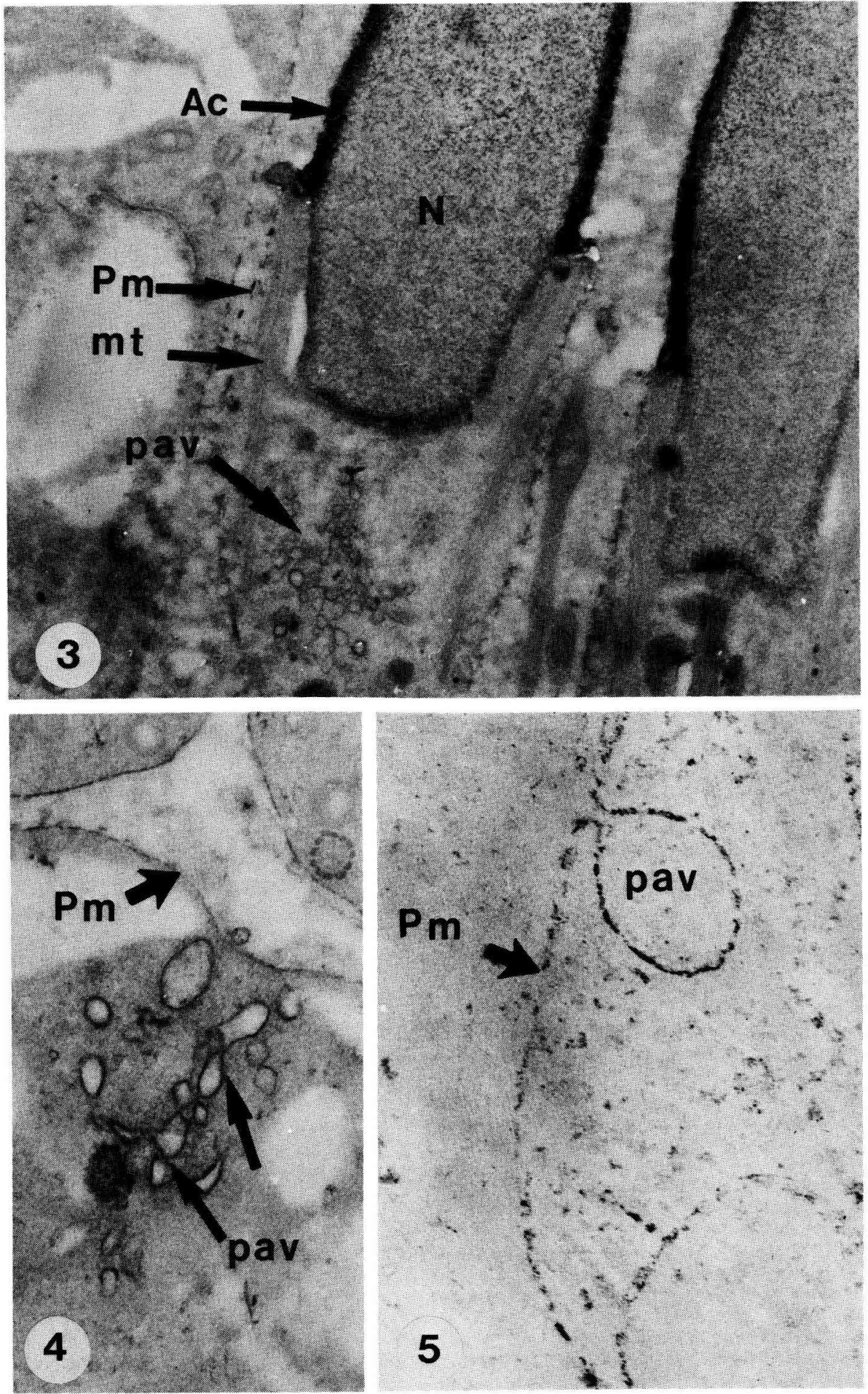
plasma membrane of stage 12 to 15 spermatids was uniformly stained, while the acrosomal membrane contrast disappeared in stage 13 spermatids (fig. 7).

At that time, the Golgi apparatus became reactive again. The only parts of testicular spermatozoa to be stained were the plasma membrane and the Golgi derivatives present in the cytoplasmic droplets. In addition to the staining of the spermatid cytoplasmic organelles described above, the nuclei of all cells in the testis were stained.

\section{Controls.}

The specific contrast of the spermatid membranes disappeared after :

- fixation of up to $1 \mathrm{hr}$ at $4^{\circ} \mathrm{C}$ or up to $30 \mathrm{~min}$. at $20^{\circ} \mathrm{C}$;

- epon embedding ;

- en bloc extraction with alcohol or acetone at $4^{\circ} \mathrm{C}$ for $3 \mathrm{hrs}$;

- treatment of the sections with alcohol (fig. 8) or acetone for $24 \mathrm{hrs}$ at $20^{\circ} \mathrm{C}$, or with 20 p. 100 acetic acid for $24 \mathrm{hrs}$ at $20^{\circ} \mathrm{C}$.

Treatment of the sections with phenylhydrazide (inhibition of aldehyde and ketone groups) for $4 \mathrm{hrs}$ at $37^{\circ} \mathrm{C}$, prior to staining, produced poor membrane staining. However, the contrast was unmodified by prior treatment of sections with 5 p. 100 sodium sulphite (inhibition of aldehyde groups) for $4 \mathrm{hrs}$ at $37^{\circ} \mathrm{C}$. All the nuclei in Spurr sections were stained by silver proteinate, and this was considered as nonspecific.

\section{Discussion.}

TCH and silver proteinate staining, developed by Thiéry (1967) as the second step of a PAS-like technique to demonstrate induced aldehydes in tissues, may also be used to visualize natural aldehydes as well as ketone groups (Ganter and Jolles, 1969). In our study this staining procedure gave reproducible pictures, if done with precision (see Material and methods).

The need for a short-duration glutaraldehyde fixation step indicated that (i) the aldehydes added to the tissues did not cause the observed contrast and (ii) the stained

\section{Plate II}

FIG. 3. - Stage 10-11 spermatid. Postacrosomal vesicles (pav) are situated in the posterior cytoplasm inside the manchette $(\mathrm{mt})$. Plasma membrane $(\mathrm{Pm})$ is more weakly and discontinuously stained. $\times 8000$.

FIG. 4. - Stage 11 spermotid. Postacrosomal vesicles (pav) are dispersed in the posterior cytoplasm outside the manchette. Some are situated near the plasma membrane $(\mathrm{Pm}) . \times 12000$.

FIG. 5. - Picture resembling the fusion of a postacrosomal vesicle (pav) with the plasma membrane of a stage 11 spermatid. The section passes through the posterior cytoplasm. $\times 36000$.

FIG. 3, 4, 5. - Thiocarbohydrazide and silver proteinate staining, $30 \mathrm{~min}$. fixation ; embedding with Spurr's medium. 

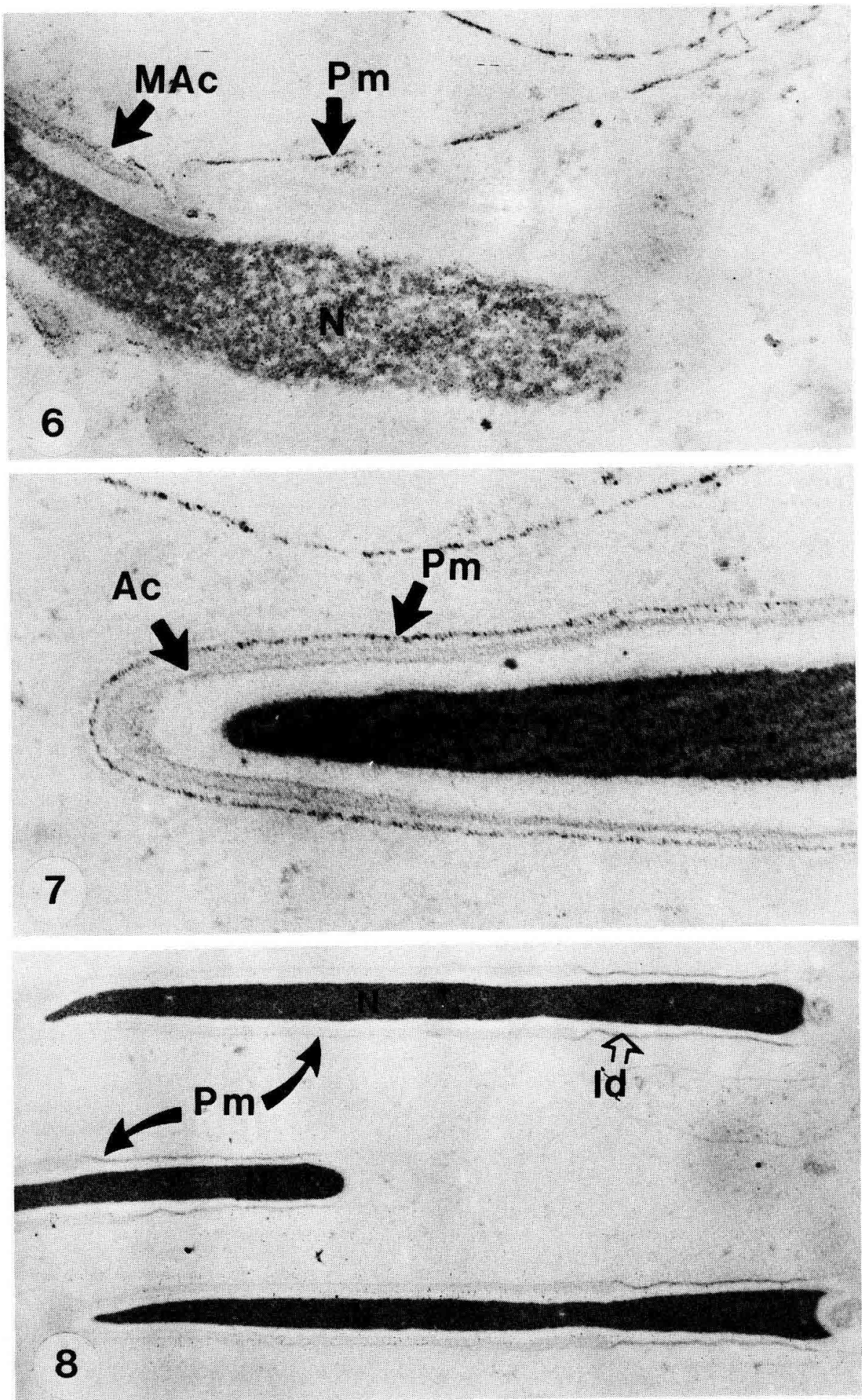
component(s) might become unreactive or be extracted during a longer fixation. Extraction with ethanol or acetone on blocs or sections indicated that the stained component(s) was lipid-associated. The necessity for embedding in Spurr medium, which is a poor lipid solvant (Wigglesworth, 1965), also suggested such a lipid composition.

The results of the phenylhydrazide and sodium sulphite treatments suggested that ketone and not aldehyde groups were involved in the TCH-affinity of the tissue component (Ganter and Jolles, 1969). However, the fact that the stained substance(s) could be easily extracted did not provide any more definite data concerning its chemical nature.

This substance(s) which is only present in spermatids in the ram testis, displayed a pattern typical within the dynamic spermiogenetic process. The participation of the Golgi apparatus in the elaboration of the plasma membrane has been recognized in a great variety of cells (Malluci ef al., 1972 ; Vian and Roland, 1972 ; for review see Morre and Ovtracht, 1977) including spermatids (Reger, 1974 ; Baccetti, 1975 ; Baccetti ef al., 1978), but acrosome contribution to this process has not yet been demonstrated. The present study shows that some components, synthesized very early in young spermatids and participating in acrosome formation, may be carried to the plasma membrane by the postacrosomal vesicles. These vesicles, only found in ram spermatids (Courtens, 1978a), have been described as cytoplasmic organelles (containing both mucosubstances and glycoproteins) emitted by the acrosome. They may be privileged vehicles for different classes of molecules to be added to the plasma membrane of old spermatids. This interpretation is based on the disappearance of the vesicle as new cyfochemical properties appear in the plasma membrane, and on the pictures obtained which resemble fusion. These pictures cannot be misinterpreted as the Sertoli cell intraspermatid indentations described in many species by Fawcett (1974) and Fouquet (1974) because they were obtained at stages 11 and 12 when Sertoli cell indentations were not yet present in the posterior cytoplasm of ram spermatids (Courtens, 1978b).

PLATE HI

FIG. 6. - Stage 11-12 spermatid. Plasma membrane ( $\mathrm{Pm})$ around the posterior cytoplasm is discontinuously stained. The portion of plasma membrane around the acrosome (MAc) is faintly positive. $\times 34000$.

FIG. 7. - Stage 14 spermatid. Plasma membrane around the head $(\mathrm{Pm})$ is stained while the acrosomal membrane $(A c)$ is negative. $\times 46000$.

FIGS. 6, 7. - Thiocarbohydrazide and silver proteinate staining. $30 \mathrm{~min}$. fixation ; embedding with Spurr's medium.

FIG. 8. - Control sections. Stage 13 spermatid. The section was treated with 100 p. 100 ethyl alcohol for $24 \mathrm{hrs}$ at $20^{\circ} \mathrm{C}$ prior to aqueous $\mathrm{TCH}$ and silver proteinate staining. The nuclei (N) remain stained while the plasma membrane $(\mathrm{Pm})$ contrast is very faint. However, the portion of membrane covering the postacrosomal lamina (ld) is less affected by alcohol extraction. $\times 15000$. 
The appearance of interrupted stained areas in the plasma membrane of elongated spermatids is not an artefact since conventional staining with uranyl acetate and/or lead citrate of adjacent sections reveals uninterrupted membranes. Thus, the progressive stainability of the plasma membranes of old spermatids may be an expression of the sequential addition of new material(s) transported to the membrane. This material might migrate inside the membrane because during spermiogenesis it was first seen in the plasma membrane around the posterior cytoplasm (with a dashed appearance) and then continuously all over that membrane. This process resembles the capping phenomenon already described in germ cells by Romrell and O'Rand (1978).

The addition of new molecules to the plasma membrane of old spermatids could be of physiological importance in spermiation or fertilization; however, the role(s) of these molecules remains to be elucidated.

Reçu en novembre 1978, Accepté en janvier 1979.

Acknowledgements. - We thank Drs $M$. Courot and $M$. Loir for critical reading of the manuscript. The technical assistance of Mr. M. Terriot is gratefully acknowledged.

Résumé. Un contraste particulier aux membranes de spermatides est obłenu après coloration par le thiocarbohydrazide ef le protéinate d'argent de coupes ultrafines de fragments de testicules de bélier, rapidement fixés ef inclus dans le milieu de Spurr. La coloration apparaît d'abord au niveau des citernes de l'appareil de Golgi puis dans les granules proacrosomiques. Ceux-ci perdent rapidement leur affinité pour le colorant tandis que la membrane de l'acrosome se colore. Les vésicules postacrosomiques (Courtens, 1978a) sont mises en évidence par cette technique. Elles migrent vers le cytoplasme postérieur des spermatides en suivant un cheminement précis avant de fusionner à la membrane plasmique. Dès lors, cette dernière acquiert progressivement la colorabilité qui est perdue par l'acrosome. Les colorations témoins suggèrent que (des) substance(s) associée(s) à des lipides, synthétisées dans l'appareil de Golgi, participent à l'élaboration de l'acrosome puis sont transférées à la membrane plasmique via les vésicules postacrosomiques.

\section{References}

BACCETTI B., 1975. The role of the Golgi complex during spermiogenesis. Curr. Top. Develop. Biol., 10, 103-122.

BACCETTI B., BIGLIARDI E., BURRINI A. G., 1978. The cell surface during mammalian spermiogenesis. Develop. Biol., 63, 187-196.

CLERMONT Y., LEBLOND C. P., 1955. Spermiogenesis of man, monkey, ram, and other mammals as shown by the periodic acid Schiff technique. Am. J. Anat., 96, 229-253.

COURTENS J. L., 1978a. Release of carbohydrate-containing vesicles by the developing acrosomes of ram spermatids. J. Ultrast. Res., 65, 182-189.

COURTENS J. L., 1978b. Cytochimie ultrastructurale de la spermiogenèse du bélier. Introduction d l'étude de quelques facteurs déterminant la différenciation des structures de la tête du spermatozoïde. Thèse Univ. Paris VI.

FAWCETT D. W., 1974. Interactions between Sertoli cells and germ cells, 13-36. In MANCINI R. E., MARTINI L., Fertility and sterility Acad. Press NY (US). Lond. (UK).

FAWCETT D. W., 1975. The mammalian spermatozoon. A review. Develop. Biol., 44, 394-436.

FOUQUET J. P., 1974. La spermiation et la formation des corps résiduels chez le hamster : rôle des cellules de Sertoli. J. Microscopie, 19, 161-168. 
GACHELIN G., FELLOUS M., GUENET J. L., JACOB F., 1976. Developmental expression of an early embryonic antigen common to mouse spermatozoa and cleavage embryos, and to human spermatozoa : its expression during spermatogenesis. Develop. Biol., 50, 310-320.

GANTER P., JOLLES C., 1969. Histochimie normole et pathologique. Gauthiers Villars, Paris.

JOHNSON W. L., HUNTER A. G., 1972. Immunofluorescent evaluation of the male rabbit reproductive tract for sites of secretion and absorption of seminal antigens Biol. Reprod., 6, 13-22.

KOEHLER J. K., 1978. The mammalian sperm surface : studies with specific labelling techniques. Int. Rev. Cytol., 34, 73-105.

LUFT J. H., 1961. Improvement in epoxy resin embedding methods. J. biophys. biochem. Cytol., 9, 409.

MALLUCI L., POSTE G. H., WELLS W., 1972. Synthesis of cell coat in normal and transformed cells. Nature, 235, 222.

MILLETTE C. F., BELLVE A. R., 1977. Temporal expression of membrane antigens during mouse spermatogenesis. J. Cell Biol., 74, 86-97.

MORRE D. J., OVTRACHT L., 1977. Dynamics of the Golgi apparafus : membrane differentiation and membrane flow. Int Rev. Cytol., suppl. 5, 61-166.

O'RAND M. G., ROMRELL L. J., 1977. Appearance of cell surface auto and isoantigens during spermatogenesis in the rabbit. Develop. Biol., 55, 347-358.

REGER J. F., 1974. The origin and fine structure of cellular process in spermatozoa of the tick Dermacentor andersoni. J. Ultrast. Res., 48, 420-434.

ROMRELL L. J., O'RAND M. G., 1978. Capping and ultrastructural localization of sperm surface isoantigen during spermatogenesis. Develop. Biol., 63, 76-93.

SPURR A., 1969. Low viscosity epoxy resin suitable for electron microscopy. J. Ultrast. Res., 26, 31-36.

THIERY J. P., 1967. Mise en évidence des polysaccharides sur coupes fines en microscopie électronique. I. Microscopie, 6, 987-1018.

TUNG P. S., FRITZ I. B., 1978. Specific surface antigens on rat spermatocytes and successive classes of germinal cells. Develop. Biol., 64, 297-315.

VIAN B., ROLAND J. C., 1972. Différenciation des cytomembranes et renouvellement du plasmalemme dans les phénomènes de sécrétion végétales. J. Microscopie, 13, 119.

WIGGLESWORTH V. B., 1965. Lipid staining for the electron microscope. A new method. J. Cell Sci. $19,425-437$. 